\title{
SPECTROPHOTOMETRIC ANALYSIS OF PIGMENTS IN HORSERADISH BY USING VARIOUS EXTRACTION SOLVENTS
}

\author{
Lolita Tomsone*, Zanda Kruma \\ Department of Food Technology, Faculty of Food Technology, Latvia University of Life Sciences and Technologies, Rigas iela 22, \\ Jelgava, Latvia,e-mail: lolita.tomsone@llu.lv
}

\begin{abstract}
Plant pigments have a wide range of nutritional benefits. Chlorophyll has antioxidant, anti-inflammatory, heavy metal chelating etc. properties, whereas carotenoids exhibit significant antioxidant activities. The aim of current research was to determine the content of chlorophyll $a$, chlorophyll $b$ and total carotenoids of frozen horseradish leaves and horseradish leave by-products depending on the used extraction solvent. For experiments, frozen horseradish leaves and horseradish leave by-products after juice extraction were extracted with four different solvents (acetone, diethyl ether, methanol and ethanol). Chlorophyll $a$, chlorophyll $b$ and total carotenoids were determined spectrophotometrically at various wavelengths (470, 645 and $662 \mathrm{~nm}$ ). Additionally, total chlorophyll content and ratio between chlorophyll $a$ and $b$ were calculated. Results showed that content of photosynthetic pigments in tested samples significantly $(\mathrm{p}<0.05)$ differed between used extraction solvents. The degree of extraction of these pigments is greatly influenced by their different chemical structures. For extraction of chlorophyll $a$ and total carotenoids the best solvent was methanol in both cases (horseradish leaves and leave by-products). But acetone was the best solvent for extraction of chlorophyll $b$. Generally, chlorophyll $a$ was detected in larger amounts in all analysed samples, better solvent was acetone, and the highest content of photosynthetic pigments were observed in horseradish leave by-products after juice extraction.
\end{abstract}

Keywords: horseradish, leaves, by-products, pigments, extraction solvents

\section{Introduction}

Plant pigments form a colour of leaves, flowers, fruits, and play an important role in the photosynthesis, growth, and control of plant development. They are very different in their structure and properties, and belong to different groups of organic compounds: tetrapyrroles (e.g. chlorophyll $a$, chlorophyll $b$ ), carotenoids (e.g. $\beta$-carotene, $\alpha$-carotene), phenolic compounds (e.g. anthocyanins, flavanols) (Schoefs, 2002). In plant leaves mainly chlorophyll $a$, chlorophyll $b$ and carotenoids are presented. These compounds are necessary for photosynthesis, so they are called photosynthetic pigments. The chemical composition of plants, as well as the content and proportions of their pigments, are very dependent on the climate, environmental conditions, variety, development stage, etc. factors (Shaikh, Dongare, 2008; Marrelli et al., 2012; Tomsone, Kruma, 2013 a). Plant pigments exhibit significant antioxidant activity by inhibiting hydroperoxide generation (Loranty et al., 2010). Different health benefits of chlorophyll pigments are proven (Ferruzzi, Blakeslee, 2007). Chlorophyll can reduce the risk of cancer because it is powerful antioxidant (Lanfer-Marquez et al., 2005; Hsu et al., 2013; Cervantes-Paz et al., 2014) and could neutralize free radicals. However, chlorophyll does not work as a major antioxidant because it is not a hydrogen donor, nor participate in hydrogen oxidation-reduction reactions (Sikorski, 2006; Belitz et al., 2009).

Chlorophyll is the most common natural pigment and is present in plant tissues in the form of colloidal suspension, taking part in photosynthesis. In reactions with alkali chlorophyll form chlorophyllide, but in reactions with acids - pheophytin. Chlorophyll is a tetrapyrrol pigment in which the porphyrin ring is in the dihydro-form. Magnesium $\left(\mathrm{Mg}^{2+}\right)$ is located in the core of the molecule, making it ionic and hydrophilic (Sumanta et al., 2014).

The porphyrin ring itself is hydrophobic, but the carbonyl group at the chain end makes it polar (Lichtenthaler, 1987; Sumanta et al., 2014). In reactions with diluted acids, it easily loses magnesium, resulting in a loss of green colour (Sikorski, 2006). Chlorophyll $a$ and chlorophyll $b$ differ only by one functional group (i.e. aldehyde group), attached to the porphyrin ring (Lichtenthaler, 1987; Sumanta et al., 2014). Chlorophyll pigments are the same in all plants, but significant colour differences are determined by the presence of other pigments that accompany chlorophyll. Carotenoids are present in chromoplasts together with chlorophylls, creating the colour of fruit and vegetables. The carotenoid group and its derivatives comprise about 70 different compounds, and they are presented in most of vegetables and fruits, performing various biological functions (Costache et al., 2012). These are photosynthetic pigments involved in photoprotection, growth and development regulation, and promote interactions between plants and environment (Ikoma et al., 2016).

Horseradish (Armoracia rusticana L.) belongs to the Crusader family and is a well-known plant in the Europe (Raghavan, 2000). More popular are horseradish roots that are used in cooking, but horseradish leaves also could be used in food production and medicine to treat several diseases (Raghavan, 2000). Previous studies have shown that horseradish leaves contain significant amounts of biologically active compounds with high antioxidant activity (Tomsone, Kruma, 2013a; Tomsone et al., 2013b). Horseradish leaves could be used as whole or as a juice, and the production of juice 
results in the formation of by-product (pomace) that had been reported by a number of scientists as a valuable source of biologically active compounds. There is no scientific information about composition of this horseradish by-product, and pigments distribution in it. The properties of pigments influence the selection of quantitative and qualitative analytical methods. Chlorophyll is a complex ester that is soluble in organic solvents (ethanol, acetone, chloroform, benzene) (Sikorski, 2006; Belitz et al., 2009), and it is necessary to determine an appropriate extraction technology (Sumanta et al., 2014). Diethyl ether (DI) is a popular solvent for chlorophyll analysis (Scheer, 1991; Porra, 2002). Also, acetone (AC) is a good solvent for the chlorophyll analysis in green plants (Ritchie, 2006), except aquatic plants (Jeffrey et al., 1997). Whereas methanol (ME) is an appropriate solvent for chlorophyll assays especially for vascular plants and algae (Porra et al., 1989; Porra, 1991; 2002). All these solvents are volatile, flammable and harmful to health (Sumanta et al., 2014). Ethanol (ET) is good solvent but is not often used for assays of pigments determination (Lichtenthaler, 1987; Rowan, 1989; Wright et al., 1997; Sumanta et al., 2014). At low pigment concentrations, good solvent is dimethyl sulphoxide (Porra et al., 1989; Porra, 2002).

The aim of the current research was to determine the content of chlorophyll $a$, chlorophyll $b$, and total carotenoids of frozen horseradish leaves and horseradish leave by-products after juice extraction depending on the used extraction solvent.

\section{Materials and Methods \\ Chemicals}

All chemicals (acetone, methanol, ethanol, diethyl ether) used in the research were obtained from Acros Organic (USA).

\section{Sample preparation}

Fresh horseradish (Armoracia rusticana L.) leaves were harvested in Jelgava, Latvia (latitude $-56^{\circ} 39^{\prime} \mathrm{N}$; longitude $-23^{\circ} 44^{\prime}$ E) in June 2018 and frozen $\left(-18 \pm 2{ }^{\circ} \mathrm{C}\right)$ and stored until further experiments. Horseradish juice was obtained using frozen sample grinding, and extracting of juice by a basket press. The resulting by-products of horseradish leaves were used for further experiments.

\section{Analytical method}

Chlorophyll $a$, chlorophyll $b$ and total carotenoid content were determined by spectrophotometric method (Sumanta et al., 2014; Straumite et al., 2015) with some modifications. Four different solvents were used: diethyl ether (DI), acetone (AC), ethanol (95\%) (ET), and methanol (ME) (Table 1). A $0.5 \mathrm{~g}$ of homogenized sample were transferred into a conical flask and extracted with $10 \mathrm{~mL}$ of an appropriate solvent with the assistance of a magnetic stirrer (magnet size $4.0 \times 0.5 \mathrm{~cm}$ ) at $700 \mathrm{rpm}$ for 15 minutes at room temperature $\left(20 \pm 1^{\circ} \mathrm{C}\right)$. The supernatant was separated by decanting. Residues were extracted again using the same procedure. Extracted supernatants were combined and filtered (filter paper No.89).

Table 1

The equations for calculation of photosynthetic pigments (Sumanta et al., 2014; Straumite et al., 2015)

\begin{tabular}{|c|c|c|}
\hline Parameter & & tions \\
\hline Solvents & DI & $\mathrm{AC}$ \\
\hline Chlorophyll $a, \mathrm{mg} \mathrm{mL}^{-1}$ & $C_{\text {Cha }}=10.05 A_{662}-0.97 A_{645}$ & $C_{\text {Cha }}=12.25 A_{662}-2.79 A_{645}$ \\
\hline Chlorophyll $b, \mathrm{mg} \mathrm{mL}^{-1}$ & $C_{C h b}=16.36 A_{645}-2.43 A_{662}$ & $C_{C h b}=21.5 A_{645}-5.1 A_{662}$ \\
\hline $\begin{array}{l}\text { Total extractable chlorophyll, } \\
\mathrm{mg} \mathrm{mL}^{-1}\end{array}$ & $C_{C h t}=C_{C h a}+C_{C h b}$ & $C_{C h t}=C_{C h a}+C_{C h b}$ \\
\hline $\begin{array}{l}\text { Ratio between chlorophyll } a \\
\text { and } b\end{array}$ & $R_{\bar{b}}=\frac{C_{C h a}}{C_{C h b}}$ & $R_{\bar{b}}=\frac{C_{C h a}}{C_{C h b}}$ \\
\hline Total carotenoids, $\mathrm{mg} \mathrm{mL}^{-1}$ & $C a=\frac{1000 A_{470}-1.43 C_{C h a}-35.87 C_{C h b}}{205}$ & $C a=\frac{1000 A_{470}-1.82 C_{C h a}-85.02 C_{C h b}}{198}$ \\
\hline Solvents & ET & ME \\
\hline Chlorophyll $a, \mathrm{mg} \mathrm{mL}^{-1}$ & $C_{\text {Cha }}=13.36 A_{662}-5.19 A_{645}$ & $C_{\text {Cha }}=16.72 A_{662}-9.16 A_{645}$ \\
\hline Chlorophyll $b, \mathrm{mg} \mathrm{mL}^{-1}$ & $C_{C h b}=27.43 A_{645}-8.12 A_{662}$ & $C_{C h b}=34.09 A_{645}-15.28 A_{662}$ \\
\hline $\begin{array}{l}\text { Total extractable chlorophyll, } \\
\mathrm{mg} \mathrm{mL}^{-1}\end{array}$ & $C_{C h t}=C_{C h a}+C_{C h b}$ & $C_{C h t}=C_{C h a}+C_{C h b}$ \\
\hline $\begin{array}{l}\text { Ratio between chlorophyll } a \\
\text { and } b\end{array}$ & $R_{\frac{a}{b}}=\frac{C_{C h a}}{C_{C h b}}$ & $R_{\frac{a}{b}}=\frac{C_{C h a}}{C_{C h b}}$ \\
\hline Total carotenoids, $\mathrm{mg} \mathrm{mL}^{-1}$ & $C a=\frac{1000 A_{470}-2.13 C_{C h a}-97.63 C_{C h b}}{209}$ & $C a=\frac{1000 A_{470}-1.63 C_{C h a}-104.96 C_{C h b}}{221}$ \\
\hline
\end{tabular}

DI - diethyl ether; AC - acetone; ET - ethanol (95\%); ME - methanol

$\mathrm{A}_{662}$-absorbance of the extract at wavelength $662 \mathrm{~nm} ; \mathrm{A}_{645}$ - absorbance of the extract at wavelength $645 \mathrm{~nm}$; $\mathrm{A}_{470}$ - absorbance of the extract at wavelength $470 \mathrm{~nm}$; $\mathrm{C}_{\mathrm{Cha}}-$ content of chlorophyll $a$; $\mathrm{C}_{\mathrm{Chb}}-$ content of chlorophyll $b$; $\mathrm{C}_{\mathrm{Cht}}-$ content of total extractable chlorophyll; $R_{\bar{b}}$ - ratio between chlorophyll $a$ and $b$; $\mathrm{Ca}$ - content of total carotenoids. 
The extraction process was performed in triplicate. Determination of chlorophyll $a$ (Ch $a$ ), chlorophyll $b$ $(\mathrm{Ch} b)$, and total carotenoids (Ca), was performed using a spectrophotometer JENWAY 6300 (Baroworld Scientifid Ltd., UK) at various wavelengths (470, 645 and $662 \mathrm{~nm}$ ). Equations used for the quantification are given in Table 1. Results were recalculated and expressed as $\mathrm{mg} \mathrm{g}^{-1}$ of plant material. All determinations were performed in triplicate. Additionally, total extractable chlorophyll content $(\mathrm{Ch} t)$ and ratio between chlorophyll $a$ and $b(\mathrm{R} a / b)$ were calculated.

\section{Statistical analysis}

Experimental results are presented as means of three parallel measurements and were analysed by Microsoft Excel 2010 and SPSS 17.00. Analysis of variance (ANOVA) and Tukey's test were used to determine differences among samples. The linear correlation analysis was performed in order to determine relationships between chlorophyll $a$, chlorophyll $b$, total chlorophyll, and total carotenoids. Differences were considered as significant at $\mathrm{p}<0.05$.

\section{Results and Discussion}

\section{Chlorophyll $a$ and chlorophyll $b$ content}

The content of chlorophyll $a$ and chlorophyll $b$ in horseradish leaves and by-products extracts depending on the used solvent is presented in Figures 1 and 2. The ANOVA analysis of variance showed that content of chlorophyll $a$ was significantly affected $(\mathrm{p}<0.05)$ by solvent and product type. The content of chlorophyll $a$ in horseradish leaves and by-products of horseradish leaves had been dependent on the used solvent and ranged from 0.46 to $0.70 \mathrm{mg} \mathrm{g}^{-1}$ and from 0.36 to $0.87 \mathrm{mg} \mathrm{g}^{-1}$, respectively. The chlorophyll $a$ is blue-green, and is considered the main pigment that converts light energy into chemical energy (Costache et al., 2012).

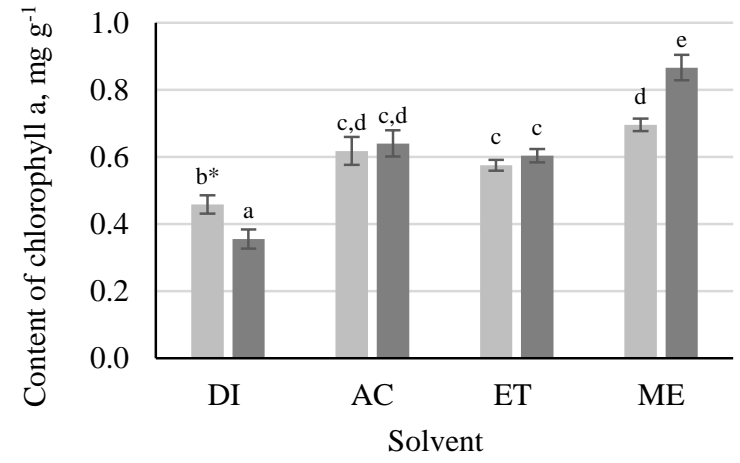

$\square$ Horseradish leaves $\square$ By-products of horseradish leaves

Figure 1. Content of chlorophyll $a$ depending on the used solvent

DI - diethyl ether, AC - acetone, ET - ethanol, ME - methanol * Similar lowercase letters indicate no significant difference among samples ( $p>0.05)$.

All solvents showed different efficiencies. Both samples expressed a similar tendency and solvents can be arranged as follows (starting from a less efficient solvent): $\mathrm{DI}<\mathrm{ET} \leq \mathrm{AC}<\mathrm{ME}$. There were no significant $(p>0.05)$ differences in the efficacy of acetone and ethanol. The better solvent for extraction of chlorophyll $a$ was methanol. The most effective were more polar solvents. The same tendency was observed in Adiantum and Drypteris species. Sumanta with colleagues (2014) found that, in the case of Crystiella species, a better solvent for extraction of chlorophyll $a$ was diethyl ether. Similarly, to analysed horseradish samples, in peppermint leaves (depending on the species) the content of chlorophyll $a$ ranged from 0.321 to $0.849 \mathrm{mg} \mathrm{g}^{-1}$ (Straumite et al., 2015). A higher content of chlorophyll $a$ was found in fresh dill (144 mg $100 \mathrm{~g} \mathrm{~g}^{-1}$ ) (Lisiewska et al., 2004). Other scientists found that the content of chlorophyll $a$ in leaves of peanut (Arachis hypogaea L.) was $1.606 \mathrm{mg} \mathrm{g}^{-1}$ (Meher et al., 2018), but in leaves of Indian mustard (Brassica juncea L.) was $11.30 \mathrm{mg} \mathrm{g}^{-1}$ (Zang, Liu, 2018). This is significantly higher than in horseradish samples in our study.

Comparing horseradish leaves and its pomace, the higher content of chlorophyll $a$ was detected in byproducts of horseradish leaves, except sample extracted using diethyl ether as solvent. In this case, a significantly $(\mathrm{p}<0.05)$ higher content of chlorophyll $a$ was detected in the horseradish leaves sample.

Also, the amount of extracted chlorophyll $b$ was significantly $(\mathrm{p}<0.05)$ affected by the used solvent (Fig. 2), similarly as in the case of chlorophyll $a$. Contrary to chlorophyll $a$, the amount of chlorophyll $b$ was not significantly $(\mathrm{p}<0.05)$ affected by the sample type, except in the case with solvent DI.

The content of chlorophyll $b$ ranged from $0.03 \mathrm{mg} \mathrm{g}^{-1}$ to $0.73 \mathrm{mg} \mathrm{g}^{-1}$ in the horseradish leave samples and $0.02-0.33 \mathrm{mg} \mathrm{g}^{-1}$ in the by-products of horseradish leaves.

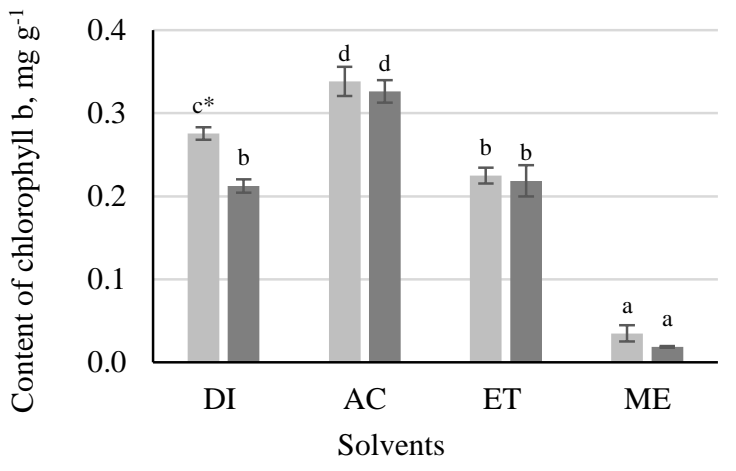

$\square$ Horseradish leaves $\square$ By-products of horseradish leaves

Figure 2. Content of chlorophyll $b$ depending on the used solvent

DI - diethyl ether, AC - acetone, ET - ethanol, ME - methanol * Similar lowercase letters indicate no significant difference among samples ( $\mathrm{p}>0.05)$.

Chlorophyll $b$ has a yellow-green colour and it absorbs blue light and therefore extends light spectrum absorbed by photosynthesis (Costache et al., 2012). 
For both analysed samples, solvents by their effectiveness can be arranged as follows (starting from a less efficient solvent): $\mathrm{ME}<\mathrm{ET} \leq \mathrm{DI}<\mathrm{AC}$. There were no significant $(\mathrm{p}<0.05)$ differences in the efficacy of diethyl ether and ethanol for by-products of horseradish leaves. The better solvent for extraction of chlorophyll $b$ was acetone. The most effective were nonpolar solvents for extraction of chlorophyll $b$. It was also reported that acetone was the best solvent for extracting chlorophyll $b$ from fern species (Adiantum species) (Sumanta et al., 2014).

A group of scientists have found that Indian mustard (Brassica juncea L.) leaves contain $5.79 \mathrm{mg} \mathrm{g}^{-1} \mathrm{FW}$ chlorophyll $b$ (Zang, Liu, 2018). It is less than in the horseradish samples analysed in this study. Other scientists found that content of chlorophyll $b$ in leaves of peanut (Arachis hypogaea L.) was significantly higher than in horseradish samples $\left(0.474 \mathrm{mg} \mathrm{g}^{-1}\right)$ (Meher et al., 2018).

Comparing both studied samples, higher contents of chlorophyll $b$ were detected in the horseradish leaves. There were no significant $(\mathrm{p}>0.05)$ differences between samples using diethyl ether and ethanol as solvent for by-products of horseradish leaves. But using diethyl ether and methanol as solvent, there was significantly $(p<0.05)$ higher content of chlorophyll $b$ in the case of horseradish leaves than for by-products of horseradish leaves.

\section{Total chlorophyll content}

The total extractable chlorophyll content was calculated using the formula shown in Table 1. Figure 3 shows the total extractable chlorophyll content in horseradish leaves and by-products depending on solvent. For analysed samples, content of total extractable chlorophyll depending on the used solvent ranged from 0.73 to $0.96 \mathrm{mg} \mathrm{g}^{-1}$ and from 0.57 to $0.97 \mathrm{mg} \mathrm{g}^{-1}$.

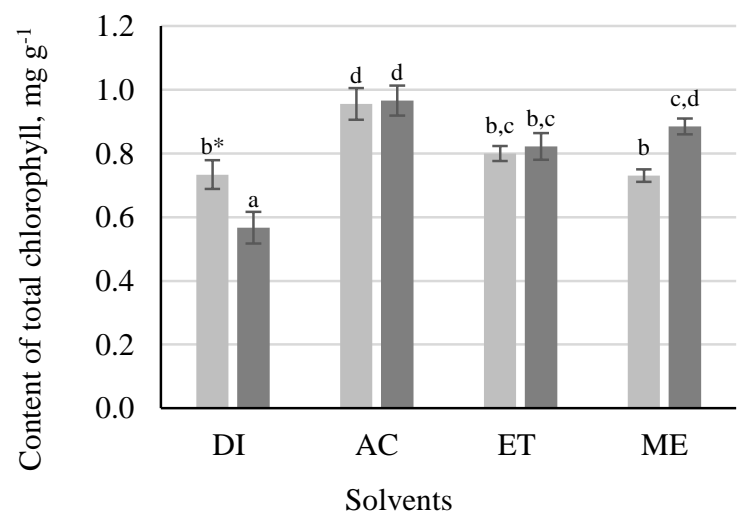

Horseradish leaves $\square$ By-products of horseradish leaves

Figure 3. Content of total extractable chlorophyll depending on the used solvent

DI - diethyl ether, AC - acetone, ET - ethanol, ME - methanol * Similar lowercase letters indicate no significant difference among samples ( $p>0.05)$.

Efficiency of different solvents to extract chlorophyll (total extractable content) from horseradish leaves byproducts can be arranged as follows (starting from a less efficient solvent): $\mathrm{DI}=\mathrm{ME}<\mathrm{ET}<\mathrm{AC}$. But for by-products of horseradish leaves solvents can be arranged as follows (starting from a less efficient solvent): $\mathrm{DI}<\mathrm{ET}<\mathrm{ME}<\mathrm{AC}$. The best solvent for extraction of total chlorophyll for both samples was acetone. Similarly, to analysed horseradish samples, in the peppermint leaves the content of total extractable chlorophyll depending on species ranged from 0.393 to $1.028 \mathrm{mg} \mathrm{g}^{-1}$ (Straumite et al., 2015). The total extractable chlorophyll content of fresh Brussels sprouts was $31.8 \mu \mathrm{g} \mathrm{g}^{-1}$ (Olivera et al., 2008). It is significantly less than in the horseradish samples analysed in this study. A significantly higher content of total extractable chlorophyll (than in horseradish samples) other scientists found in leaves of peanut (Arachis hypogaea L.) (2.08 $\left.\mathrm{mg} \mathrm{g}^{-1}\right)$ (Meher et al., 2018) and in leaves of Indian mustard (Brassica juncea L.) (17.10 $\mathrm{mg} \mathrm{g}^{-1}$ ) (Zang, Liu, 2018).

There are no significant $(\mathrm{p}>0.05)$ differences between total extractable chlorophyll content comparing horseradish leaves and by-products of horseradish leaves using acetone. The same situation was detected with ethanol. The results showed that chlorophyll mainly remains in by-products and was not extracted in juice and that it is possible to extract chlorophyll from the horseradish only with the help of a solvent.

\section{Ratio between chlorophyll $a$ and $b$}

The ratios between chlorophyll $a$ and $b$ were calculated (Table 1) and results are shown in Figure 4.

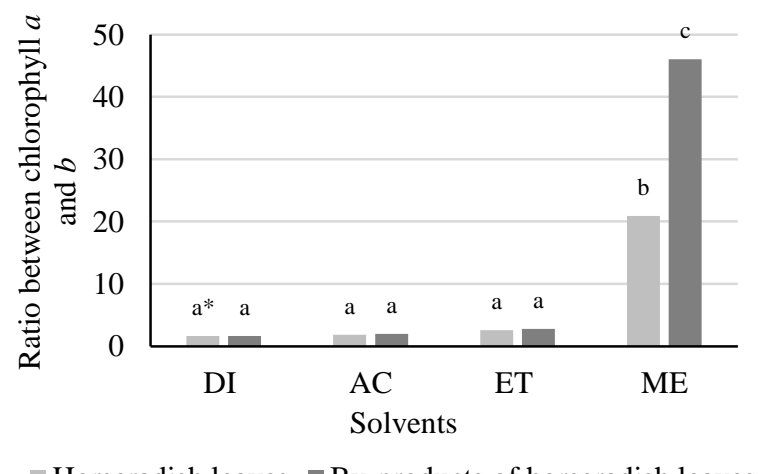

Horseradish leaves By-products of horseradish leaves

Figure 4. Ratio between chlorophyll $a$ and $b$ depending on the used solvent

DI - diethyl ether, AC - acetone, ET - ethanol, ME - methanol * Similar lowercase letters indicate no significant difference among samples ( $\mathrm{p}>0.05)$.

Ratio ranged from 1.66 (DI) to 20.86 (ME) for horseradish leaves and 1.67 (DI) to 46.04 (ME) for by-products of horseradish leaves. In both analysed samples, the content of chlorophyll $a$ was significantly higher than the content of chlorophyll $b$. This shows that chlorophyll $a$ is the main chlorophyll form in analysed horseradish samples. The results showed that methanol was a better solvent for extraction of chlorophyll $a$ and not suitable solvent for extraction of chlorophyll $b$, especially for by-products of horseradish leaves, resulting in a high ratio. 
It had been reported that the ratio between chlorophyll $a$ and chlorophyll $b$ in fresh Brussels sprouts could reach 2.43 using $80 \%$ (v/v) acetone (Olivera et al., 2008). It is similar to our results of chlorophyll extraction from both horseradish samples using ethanol as a solvent but more when using acetone as a solvent. A significantly higher proportion of chlorophyll $a$ had been reported in mint leaves and it ranged from 3.79 to 7.64 (Straumite et al., 2015). As the solubility of chlorophyll was significantly different in different solvents, the real proportion of chlorophyll $a$ and $b$ content in horseradish leaves and leaf presses is 2.01 and 2.62, respectively. This value is obtained by dividing the amount of extracted chlorophyll $a$ (ME) by the quantity of extracted chlorophyll $b$ (AC).

\section{Total carotenoids analysis}

The content of total carotenoids in horseradish leaves and by-products extracts depending on the solvent is shown in Figure 5. ANOVA analysis of variance showed that the content of total carotenoids was significantly affected $(\mathrm{p}<0.05)$ by solvent and by analysed samples. Content of total extractable carotenoids in horseradish leaves and by-products of horseradish leaves depending on the used solvent ranged from 0.1 to $0.25 \mathrm{mg} \mathrm{g}^{-1}$ and from 0.09 to $0.32 \mathrm{mg} \mathrm{g}^{-1}$, respectively.

The tendency had been observed, that the content of total carotenoids increased in unison with the increase in solvent polarity. Solvents by their effectiveness can be arranged as follows (starting from a less efficient solvent): $\mathrm{DI} \leq \mathrm{AC}<\mathrm{ET}<\mathrm{ME}$. The better solvent for extraction of total carotenoids was methanol.

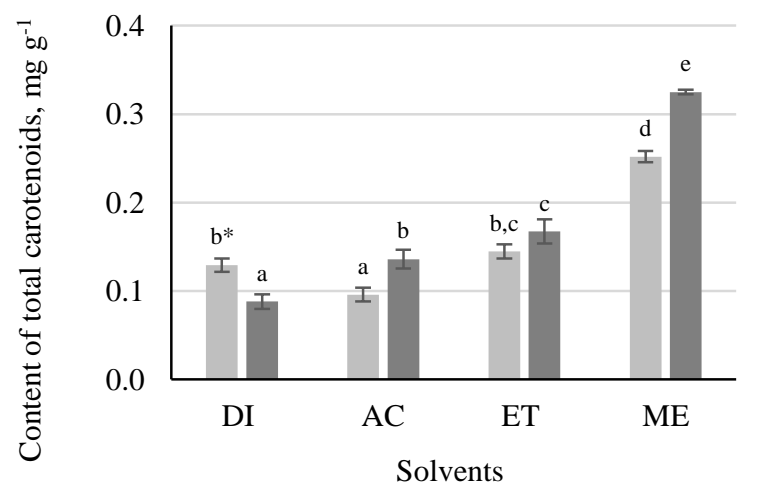

$\square$ Horseradish leaves $\square$ By-products of horseradish leaves

\section{Figure 5. Content of total carotenoids depending on} the solvent used

DI - diethyl ether, AC - acetone, ET - ethanol, ME - methanol * Similar lowercase letters indicate no significant difference among samples ( $p>0.05)$.

The solvents used can be ranked by their polarity as follows (starting from more unpolar solvents): $\mathrm{DI}<\mathrm{AC}<\mathrm{ET}<\mathrm{ME}$. For both analysed samples it is possible to see an increase in total carotenoids content by an increased polarity of solvent. Sumanta with colleagues (2014) reported that methanol is one of the best solvents for total carotenoid extraction for
Drypteris species and it is similar to analysed horseradish samples. In the case of Adiantum species, the best solvent for carotenoid analysis is acetone (Sumanta et al., 2014). Comparing both samples, more total carotenoids were detected in the by-products of horseradish leaves, except using diethyl ether as a solvent.

\section{Correlation analysis}

The correlation analysis was performed to determine relationships between photosynthetic pigments. For horseradish leaves and by-products of horseradish leaves correlation between total chlorophyll and chlorophyll $a$ was very strong positive (0.949).

But the correlation between total chlorophyll and chlorophyll $b$ was positive strong (0.787). This means that as one parameter increases, the other increase too. The medium and positive correlation was observed between chlorophyll $a$ and chlorophyll $b(0.557)$ and between chlorophyll $a$ and total carotenoids (0.538).

\section{Conclusions}

Results showed that content of photosynthetic pigments in extracts were significantly $(\mathrm{p}<0.05)$ affected by analysed sample, and solvent used. The degree of extraction of these pigments is greatly influenced by chemical nature of bio-molecules (chlorophyll $a$, chlorophyll $b$ and carotenoids). For extraction of chlorophyll $a$ and total carotenoids the best solvent was methanol in both cases (horseradish leaves and byproducts). But acetone was the best solvent for extraction of chlorophyll $b$ and total chlorophyll. Chlorophyll $a$ comparing to chlorophyll $b$ was detected in larger amounts in the analysed samples. After the calculation, the content of total extractable chlorophyll was higher in extracts acquired using acetone as a solvent. Overall the better solvent was acetone and the highest content of photosynthetic pigments had been observed in horseradish by-products.

\section{Acknowledgment}

This study was financially supported by the ERDF Post-doctoral Research Support Program (project Nr.1.1.1.2/16/I/001) Research application "The changes of horseradish biologically active compounds and their bioavailability in an in vitro model of the human gastrointestinal tract as a result of technological processes" (Nr.1.1.1.2./VIAA/1/16/187).

\section{References}

1. Belitz H.-D., Grosch W., Schieberle P. (2009) Food Chemistry. $4^{\text {th }}$ revised edition. Edited by: M. Burghagen. Berlin, Heidelberg: Springer-Verlag. 1070 p.

2. Cervantes-Paz B., Yahia E.M., De J.O.J., VictoriaCampos C.I., Ibarra-Junquera V., Pérez-Martínez J.D., Escalante-Minakata P. (2014) Antioxidant activity and content of chlorophylls and carotenoids in raw and heatprocessed Jalapeno peppers at intermediate stages of ripening. Food Chemistry, Vol. 146, p. 188-196.

3. Costache M.A., Campeanu G., Neata G. (2012) Studies concerning the extraction of chlorophyll and total 
carotenoids from vegetables. Romanian Biotechnolo. Letters, Vol. 17(5), p. 7702-7708.

4. Ferruzzi M.G., Blakeslee J. (2007) Digestion, absorption, and cancer preventative activity of dietary chlorophyll derivatives. Nutrition Research, Vol. 27(1), p. 1-12.

5. Hsu C.Y., Chao P.Y., Hu S.P., Yang C.M. (2013) The antioxidant and free radical scavenging activities of chlorophylls and pheophytins. Food \& Nutrition Sciences, Vol. 4(8), p. 1-8.

6. Ikoma Y., Matsumoto H., Kato M. (2016) Diversity in the carotenoid profiles and the expression of genes related to carotenoid accumulation among citrus genotypes. Breeding Science, Vol. 66, p. 139-147.

7. Jeffrey S.W., Mantoura, R.F.C., Wright S.W. (1997) Phytoplankton pigments in oceanography: guidelines to modern methods. UNESCO monographs on oceanographic methodology, UNESCO Publishing, Paris, 10.

8. Lanfer-Marquez U.M., Barros R.M.C., Sinnecker P. (2005) Antioxidant activity of chlorophylls and their derivatives. Food Research International, Vol. 38(8-9), p. 885-891.

9. Lichtenthaler H. K. (1987) Chlorophylls and carotenoids: pigments of photosynthetic membranes. Methods in Enzymolpgy, Vol. 148, p. 350-382.

10. Lisiewska Z., Kmiecik W., Słupski J. (2004) Contents of chlorophylls and carotenoids in frozen dill: effect of usable part and pre-treatment on the content of chlorophylls and carotenoids in frozen dill (Anethum graveolens L.), depending on the time and temperature of storage. Food Chemistry, Vol. 84, p. 511-518.

11. Loranty A., Rembiałkowska E., Rosa E.S., Bennett R.N. (2010) Identification, quantification and availability of carotenoids and chlorophylls in fruit, herb and medicinal teas. Journal of Food Composition and Analysis, Vol. 23(5), p. 432- 441.

12. Marrelli M., Menichini F., Statti G.A., Bonesi M., Duez P., Menichini F., Conforti F. (2012) Changes in the phenolic and lipophilic composition, in the enzyme inhibition and antiproliferative activity of Ficus carica L. cultivar Dottato fruits during maturation. Food and Chemical Toxicology, Vol. 50(3-4), p. 726-733.

13. Meher S.P., Ashok R.K., Manohar R.D. (2018) Effect of PEG-6000 imposed drought stress on RNA content, relative water content (RWC), and chlorophyll content in peanut leaves and roots. Saudi Journal of Biological Sciences, Vol. 25, p. 285-289.

14. Olivera D.F., Vina S.Z., Marani C.M., Ferreyra R.M., Mugridge A., Chaves A.R., Mascheroni R.H. (2008) Effect of blanching on the quality of Brussels sprouts (Brassica oleracea L. gemmifera DC) after frozen storage. Journal of Food Engineering, Vol. 84(1), p. 148-155.

15. Porra R.J., Thompson W.A., Kreidemann P.E. (1989) Determination of accurate extinction coefficients and simultaneous equations for assaying chlorophylls a and b extracted with four different solvents: verification of the concentration of chlorophyll standards by atomic absorption spectrometry. Biochimica et Biophysica Acta, Vol. 975, p. 384-394.
16. Porra R. J. (1991) Recent advances and re-assessments in chlorophyll extraction and assay procedures for terrestrial, aquatic, and marine organisms, including recalcitrant algae. In: Scheer H (ed) Chlorophylls, p. 31-57.

17. Porra R.J. (2002) The chequered history of the development and use of simultaneous equations for the accurate determination of chlorophylls $a$ and $b$. Photosynthesis Research, Vol. 73, p. 149-156.

18. Raghavan Uhl S. (2000) A to Z Spices. In: Handbook of Spices, Seasonings, and Flavorings, Horizons Consulting, Boca Raton, London, New York, Washington, D.C., p. 59-60.

19. Ritchie R.J. (2006) Consistent sets of spectrophotometric chlorophyll equations for acetone, methanol and ethanol solvents. Photosynthesis Research, Vol. 89, p. 27-41.

20. Rowan K. S. (1989) Photosynthetic pigments of algae. Cambridge University Press, Cambridge.

21. Scheer H., (ed) Chlorophylls. CRC Press Boca Raton, Ann Arbor, Boston, Landon, 31-57 (1991).

22. Schoefs B. (2002) Chlorophyll and carotenoid analysis in food products. Properties of the pigments and methods of analysis. Trends in Food Science and Technology, Vol. 13, p. 361-371.

23. Shaikh S.D., Dongare M. (2008) Analysis of photosynthesis pigments in Adiantum lunulatum Burm. At different localities of Sindhudurg district (Maharastra). Indian Fern Journal, Vol. 25, p. 83-86.

24. Sikorski Z.E. (2006) Chemical and Functional Properties of Food Components, 3rd edition, Ed. by Z.E.Sikorski, CRC Press 2006, 544 p.

25. Straumite E., Kruma Z., Galoburda R. (2015) Pigments in mint leaves and stems. Agronomy Research, Vol. 13(4), p. $1104-1111$.

26. Sumanta N., Haque C.I, Nishika J., Suprakash R. (2014) Spectrophotometric analysis of chlorophylls and carotenoids from commonly grown fern species by using various extracting solvents. Research Journal of Chemical Sciences, Vol. 4(9), p. 63-69.

27. Tomsone L., Kruma Z. (2013a) Comparison of different solvents for isolation of phenolic compounds from horseradish (Armoracia rusticana L.) leaves. In: Research for Rural Development 2013: annual 19th international scientific conference proceedings, Jelgava, Latvia, Vol. 1, p. 104-110.

28. Tomsone L., Kruma Z., Galoburda R., Dimins F., Kreicbergs V. (2013b) Influence of technological processes on the phenol content and antioxidant properties of horseradish roots (Armoracia rusticana L.). In: 2nd International conference on Nutrition and Food Sciences „International Proceedings of Chemical, Biological and Environmental Engineering”: International Conference proceedings, Moscow, Russia, Vol. 53, p.6-10.

29. Zhang Y., Liu G. (2018) Effects of cesium accumulation on chlorophyll content and fluorescence of Brassica juncea L. Journal of Environmental Radioactivity, Vol. 195, p. 2026-2032.

30. Wright S.W., Jeffrey S.W., Mantoura F.R.C. (1997) Evaluation of methods and solvents for pigment analysis. In: Phytoplankton pigments in oceanography: guidelines to modern methods, UNESCO Publ., Paris, p. 261-282. 